\title{
Characterization of the Key Aroma Constituents in Fry Breads by Means of the Sensomics Concept
}

\author{
Ola Lasekan * (D) and Fatma Dabaj \\ Department of Food Technology, University Putra Malaysia, Serdang UPM 43400, Malaysia; fdabaj@yahoo.co.uk \\ * Correspondence: olaniny56@gmail.com
}

Received: 8 July 2020; Accepted: 22 July 2020; Published: 17 August 2020

\begin{abstract}
The key aroma constituents in the volatile fractions isolated FROM two differently processed fry breads by solvent-assisted flavor evaporation were characterized by an aroma extract dilution analysis (AEDA). Twenty-two compounds were identified with flavor dilution (FD) factor ranges of 2-516. Among them, 13 compounds (FD $\geq 16$ ) were quantified by stable isotope dilution assays and analyzed by odor activity values (OAVs). Of these, 11 compounds had OAVs $\geq 1$, and the highest concentrations were determined for $\delta$-decalactone and 2,3-butanedione. Two recombination models of the fry breads showed similarity to the corresponding fry breads. Omission tests confirmed that aroma-active constituents, such as $\delta$-decalactone (oily/peach), 2-acetyl-1-pyrroline (roasty/popcorn-like), 3-methylbutanal (malty), methional (baked potato-like), 2,3-butanedione (buttery), phenyl acetaldehyde (flowery), (E,E)-2,4-decadienal (deep-fried), butanoic acid, and 3-methylbutanoic acid, were the key aroma constituents of fry bread. In addition, 3-methoxy-4-vinylphenol (smoky) and 4-hydroxy-2,5-dimethyl-3(2H)-furanone were also identified as important aroma constituents of fry bread.
\end{abstract}

Keywords: aroma constituents; aroma extract dilution analysis; fry bread; odor activity values; solvent-assisted flavor evaporation

\section{Introduction}

Fry bread or scone is Native American bread widely consumed in the United States. Fry bread is produced from frozen or unfrozen flat dough which is fried or deep-fried in oil, shortening or lard. Fry breads' formulation is quite similar to that of bread rolls: flour, sugar, powdered milk, salt, and water. While bread is simply a mixture of flour, water, yeast, and salt with or without butter in the right proportions, kneaded, fermented, and baked in an oven [1]; fry bread formula is devoid of yeast, and the dough is deep-fried at a temperature of $176.7^{\circ} \mathrm{C}$. The quality of fry bread is normally defined by its texture, color and flavor (i.e., the sum of the gustative and olfactory responses observed during food consumption) [2]. Among these qualities, the flavor of fry bread, as in other bread types, is one of the most important factors that determine its acceptance by consumers [3].

The flavor of bread as well as the key aroma compounds responsible for its characteristic flavor has been well documented [4-6]. Oftentimes the flavor of bread is brought about by the interaction of a large number of compounds which exhibit different olfactive characteristics. Some of these compounds include pyrazines, aldehydes, esters, ketones, acids, alcohols, hydrocarbons, pyrrolines, furans, etc. [2,3]. Other determinant factors influencing the odor quality of bread are the type of flour, type of fermentation [7], dough improvers [8], and production process [9]. While more than 540 volatiles have been identified in bread [10], only a small fraction of these volatile compounds plays a significant role in the bread's aroma [1]; interestingly, these small fractions are the ones detectable by the human olfactory receptors. In recent times, the development of extraction methods and analytical procedures has been employed to identify these volatile fractions $[4,11,12]$. However, most of 
the methods employed for the quantitation of these volatile fractions are usually carried out with external calibration without necessarily addressing losses during the workup procedure. To address this issue, stable isotope dilution assays (SIDAs) in combination with gas chromatography-mass spectrometry-olfactometry as well as the calculation of odor activity values (OAVs) are now being employed [13,14]. Currently there are many documented reports on the volatile constituents of bread. However, for Native Americans, with an estimated population of 42 million [15], fry bread is primarily a food for special occasion, similar to cake [16]. It can be served as a savory meal topped with cheese or meat. However, the flavor characteristic of this product, which is eaten across the United States, has not been reported to the best of our knowledge.

Therefore, there is a need for a concerted effort to elucidate the flavor compounds in fry bread. This study was therefore aimed at characterizing the key aroma constituents of fry bread using the sensomics approach. The sensomics approach is the best method to date for identifying compounds which play an active role in aroma perception. The approach can also be used to isolate taste components in food along with aroma compounds [17]. In addition, while other flavor analytical techniques rely on separation-based chromatographic methods to quantify the aroma strength of individual compounds in a food matrix, the sensomics approach combines the aforementioned techniques with reconstitution and omission experiments to evaluate the role of specific compounds in the perceived aroma of a mixture. The practical fallout of this approach is the so-called flavor blueprint or flavor signature of a food, i.e., the combinatorial code of the entire set of odor- and taste-active food components in their natural concentrations in food [18]. Furthermore, the sensomics approach has been employed in the characterization of aroma compounds of yeast dough dumpling [14] and the crust of soft pretzels [13].

\section{Materials and Methods}

\subsection{Fry Bread Production}

Fry breads were produced by employing the two commonly used methods by Native North Americans. Fry bread can be made from either frozen $\left(-30^{\circ} \mathrm{C}\right)$ or freshly made doughs. The dough recipes contained high protein $(13 \%)$ (enriched bakers patent flour from Pastry Product, Sdn., Malaysia) $(1000 \mathrm{~g})$; warm water $\left(550 \mathrm{~g}, 50^{\circ} \mathrm{C}\right)$; salt $(15 \mathrm{~g})$; granulated sugar $(30 \mathrm{~g})$; powdered milk $(15 \mathrm{~g})$; and baking powder $(30 \mathrm{~g})$. The flour, salt, granulated sugar, and baking powder were mixed separately in a large bowl. The powdered milk was dissolved in the warm water and subsequently added slowly to the dry mixture. The ingredients were introduced into a mixer (Stephan, Hameln, Germany) and mixed for $3 \mathrm{~min}$ to produce fluffy dough. The dough mass was divided into 8 golf ball-sized pieces. Four of the golf ball-sized pieces (A) were kept frozen $\left(-30^{\circ} \mathrm{C}\right)$ for $24 \mathrm{~h}$. The other four pieces (i.e., unfrozen) (B) were allowed to rise in a warm spot $\left(29 \pm 2{ }^{\circ} \mathrm{C}\right)$ for approximately $20 \mathrm{~min}$. Each of the dough pieces was flattened with a rolling pin to approximately $0.102-0.127 \mathrm{M}$ circular discs and fried in 0.051 to $0.076 \mathrm{M}$ sunflower oil maintained at $180^{\circ} \mathrm{C}$ in a mini electric frying pan (Model/SKU 745409792, Helenite). The flattened dough pieces were fried on each side for about $15 \mathrm{~s}$. The golden-brown fry breads (UFBs) (approximately $0.153 \mathrm{M}$ ) were removed and drained on a paper towel. The frozen dough pieces (A) were removed after $24 \mathrm{~h}$ and kept in a zippered plastic bag inside a fridge overnight to defrost. The thawed dough pieces were flattened into circular discs $(0.102-0.127 \mathrm{M})$ and fried (FBs) as described earlier.

\subsection{Chemicals}

The pure samples of the following compounds: nonanal, 2,3-butanedione (diacetyl), acetic acid, 3-methylbutanal, butanoic acid, 2-methylpropanoic acid, 3-methylbutanoic acid, pentanoic acid, octanoic acid, and hexanoic acid were purchased from Merck (Darmstadt, Germany). (E)-2-nonenal, 2-nonanone, phenyl acetaldehyde, $\delta$-decalactone, 2-methoxy-4-vinylphenol, 4,5-epoxy-(E)-2-decanal, $(E, E)$-2,4-decadienal, (Z)-2-nonenal, methional, and 4-hydroxy-2,5-dimethyl-3 (2H)-furanone were from Sigma-Aldrich (Taufkirchen, Germany). 1-Octen-3-one was from Symrise (Holzminden, Germany). 
The following labelled compounds were synthesized according to the literature cited; $\left[{ }^{2} \mathrm{H}_{2}\right]$-Butanoic acid [19]; 3-[ $\left[{ }^{2} \mathrm{H}_{2}\right]$-methylbutanal [11]; $\left[{ }^{2} \mathrm{H}_{2-5}\right]$-2-acetyl-1-pyrroline [20]; $\left[{ }^{13} \mathrm{C}_{4}\right]-2,3$-butanedione [21]; [2 $\mathrm{H}]-(E, E)-2,4-d e c a d i e n a l ~[22] ;\left[{ }^{13} \mathrm{C}_{2}\right]$-acetic acid [22]; $\left[{ }^{2} \mathrm{H}_{2}\right]-3$-methylbutanoic acid [23]; $\left[{ }^{2} \mathrm{H}_{3}\right]-2-$ methoxyphenol [24]; [ $\left.{ }^{2} \mathrm{H}_{5}\right]$-phenyl acetaldehyde [25]; $\left[{ }^{13} \mathrm{C}_{2}\right]-4$-hydroxy-2,5-dimethyl-3(2H)furanone [26]; $\left[{ }^{2} \mathrm{H}_{2}\right]-\delta$-decalactone [27]; $\left[{ }^{2} \mathrm{H}_{2}\right]$-methional [27]. Lastly, $\left[{ }^{2} \mathrm{H}_{3}\right]$-hexanoic acid was from Cambridge Isotope Laboratories (Euriso-top GmbH, Saarbrucken, Germany).

\subsection{Isolation of Volatiles from Pulverized Fry Bread for Aroma Extracts Dilution Analysis (AEDA)}

Fry breads (i.e., UFBs and FBs) were each $(150 \mathrm{~g})$ sliced into pieces and frozen separately in liquid nitrogen. The frozen bread pieces were pulverized in a warring blender. The volatiles from the pulverized crumb $(150 \mathrm{~g})$ were extracted at room temperature $\left(30 \pm 2{ }^{\circ} \mathrm{C}\right)$ with dichloromethane $(350 \mathrm{~mL}, 1 \mathrm{~h})$, and the extract was subsequently distilled at $40{ }^{\circ} \mathrm{C}$ using the solvent-assisted flavor evaporation (SAFE) distillation protocol [28]. The distillate was treated with aqueous sodium carbonate solution $(0.5 \mathrm{~mol} / \mathrm{L}, 50 \mathrm{~mL} \times 3)$ to remove the acidic volatiles [29]. Furthermore, the aqueous solution was washed with dichloromethane $(50 \mathrm{~mL})$, and the organic phases were combined and dried over anhydrous sodium sulphate. It was filtered and concentrated to $1 \mathrm{~mL}$ with a small size Vigreux column $(40 \mathrm{~cm} \times 1 \mathrm{~cm})$. All analyses were repeated in triplicate.

\subsection{Analysis of Volatiles}

\subsubsection{Gas Chromatography-Mass Spectrometry Analysis}

The volatile constituents of the fry bread extracts were analyzed by the GC-MS system (GC-MS, QP-5050A, Shimadzu, Kyoto, Japan) equipped with a ( $30 \mathrm{~m} \times 0.32 \mathrm{~mm}, 0.5 \mu \mathrm{m}$ film thickness) DB-WAX (J \& W Scientific, Folsom, USA) column. The extracts $(2 \mu \mathrm{L})$ were applied by the on-column injection technique at $220^{\circ} \mathrm{C}$. The temperature of the oven was raised from $40{ }^{\circ} \mathrm{C}$. $\mathrm{Min}^{-1}$ to $50{ }^{\circ} \mathrm{C}$, held for $2 \mathrm{~min}$ isothermally, and then raised from $4{ }^{\circ} \mathrm{C}$. $\mathrm{Min}^{-1}$ to $250^{\circ} \mathrm{C}$. The flow rate of the carrier helium was $2.0 \mathrm{~mL} \mathrm{Min}{ }^{-1}$. The retention indices (RIs) of the compounds were calculated as described previously [29].

Mass spectra were recorded in the electron impact positive mode (EI) over a scan range of $\mathrm{m} / \mathrm{z}$ 40-270 (scan frequency $5.8 \mathrm{~Hz}$ ) applying an electron energy of $70 \mathrm{eV}$. The total run time was $45 \mathrm{~min}$. The source and transfer line temperatures were 200 and $240{ }^{\circ} \mathrm{C}$, respectively. Mass spectra were evaluated using the Xcalibur software (Thermos Scientific, Dreieich, Germany).

\subsubsection{Gas Chromatography-Olfactometry (GC-O)}

In order to identify the aroma-active constituents in the fry bread extracts, an olfactory detection port ODP-3 (Gestalt, Mulheim, Germany) which was connected to a Trace Ultra 1300 gas chromatograph (Thermos Scientific, Waltham, MA, USA) was used to conduct the sniffing test. The GC-O system was fitted with a DB-Wax column $(30 \mathrm{~m} \times 0.32 \mathrm{~mm}$ and $0.5 \mu \mathrm{m}$ film thickness, J \& W Scientific, Folsom, CA, USA). Sniffing was conducted as described previously [30]. Three experienced panelists (two females and a male) with strong gustative and olfactory responses in earlier sessions were used for the sniffing test. The sniffing analysis was divided into three sessions of $20 \mathrm{~min}$, and each assessor participated in the exercise. All analyses were repeated in triplicate by each assessor.

\subsubsection{Aroma Extracts Dilution Analysis (AEDA)}

The flavor dilution (FD) factors of the aroma constituents were determined by GC-O as reported by Lasekan and Yap [30]. The original extracts $(200 \mu \mathrm{L})$ containing the neutral/basic volatile constituents obtained from the pulverized fry bread $(150 \mathrm{~g})$ were diluted in a stepwise fashion by the addition of dichloromethane as described earlier [30]. Three panelists evaluated all dilutions in triplicate. Only the aroma compounds detected by more than two panelists were recorded. 


\subsection{Aroma Constituents' Quantification by Stable Isotope Dilution Assays (ACQSIDAs)}

Labelled standards (10-60 $\mu \mathrm{g})$ which were earlier dissolved in dichloromethane $(5 \mathrm{~mL})$ were added to each pulverized fry bread sample $(100 \mathrm{~g})$. The extract was distilled using the SAFE distillation method described earlier in Section 2.3. Aliquots $(0.5 \mu \mathrm{L})$ of the concentrates were analyzed by means of two-dimensional GC-MS as described previously [31]. The calibration factor for each compound was determined by analyzing mixtures of the defined quantity of the labelled compounds in five different mass ratios (1:5, 1:3, 1:1, 3:1, and 5:1) using the GC-MS. The obtained response factors from the peak area and the amounts of labelled compound are shown in Table 1.

Table 1. Selected ions and calibration factors used for the quantification of aroma compounds in fry bread by stable isotope dilution assays.

\begin{tabular}{|c|c|c|c|c|c|}
\hline Number & Compounds ${ }^{a}$ & $\begin{array}{l}\text { Selected } \\
\text { Ions }(\mathrm{m} / \mathrm{Z})\end{array}$ & Internal Standards & $\begin{array}{l}\text { Selected } \\
\text { Ions }(\mathrm{m} / \mathrm{z})\end{array}$ & $\begin{array}{l}\text { Calibration } \\
\text { Factor }\end{array}$ \\
\hline 1 & Acetic acid & 61 & {$\left[{ }^{13} \mathrm{C}_{2}\right]$-acetic acid } & 63 & 1.00 \\
\hline 2 & 3-Methylbutanoic acid & 60 & {$\left[{ }^{2} \mathrm{H}_{2}\right]$-3-methylbutanoic acid } & 62 & 1.00 \\
\hline 3 & 2,3-Butanedione & 87 & {$\left[{ }^{2} \mathrm{H}_{2}\right]-2,3$-butanedione } & 91 & 0.90 \\
\hline 4 & 3-Methylbutanal & 87 & {$\left[{ }^{2} \mathrm{H}_{2}\right]-3$-methylbutanal } & 89 & 1.00 \\
\hline 5 & Butanoic acid & 89 & {$\left[{ }^{2} \mathrm{H}_{2}\right]$-butanoic acid } & 91 & 0.95 \\
\hline 6 & Methional & 105 & {$\left[{ }^{2} \mathrm{H}_{2}\right]$-methional } & 108 & 1.00 \\
\hline 7 & 2-Acetyl-1-pyrroline & 112 & {$\left[{ }^{2} \mathrm{H}_{2}\right]$-2-acetyl-1-pyrroline } & 114 & 1.00 \\
\hline 8 & Hexanoic acid & 117 & {$\left[{ }^{2} \mathrm{H}_{2}\right]$-hexanoic acid } & 120 & 0.95 \\
\hline 9 & Phenyl acetaldehyde & 121 & {$\left[{ }^{2} \mathrm{H}_{2}\right]$-2-phenyl acetaldehyde } & 123 & 0.85 \\
\hline 10 & $\begin{array}{l}\text { 4-Hydroxy-2,5- } \\
\text { dimethyl-3(2H)- furanone }\end{array}$ & 129 & $\begin{array}{l}{\left[{ }^{13} \mathrm{C}_{2}\right]-4 \text {-hydroxy-2,5- }} \\
\text { dimethyl-3(2H)-furanone }\end{array}$ & 131 & 1.00 \\
\hline 11 & 2-Methoxy-4-vinylphenol & 150 & {$\left[{ }^{13} \mathrm{C}_{6}\right]$-2-methoxy-4-vinylphenol } & 156 & 0.85 \\
\hline 12 & $(E, E)$-2,4-decadienal & 153 & {$\left[{ }^{2} \mathrm{H}_{2}\right]-(\mathrm{E}, \mathrm{E})-2,4$-decadienal } & 156 & 0.97 \\
\hline 13 & $\delta$-Decalactone & 171 & {$\left[{ }^{2} \mathrm{H}_{2}\right]-\delta$-decalactone } & 173 & 1.00 \\
\hline
\end{tabular}

a The compounds and calibration factors were determined as reported previously by Lasekan, Buettner, and Christlbauer (2007) [31] and Guth and Grosch (1993) [32], respectively.

\subsection{Aroma Profile Determination}

An hour after frying, the pulverized fry breads (i.e., UFBs and FBs) (approximately $8 \mathrm{~g}$ with similar crust covering) were placed inside glass beakers (height $7 \mathrm{~cm}$, volume $45 \mathrm{~mL}$ ) with three random digitals and orthonasally analyzed by panel members at room temperature $\left(29 \pm 2{ }^{\circ} \mathrm{C}\right)$. In addition, samples were rotated among panelists to avoid a carry-over effect. The panel was made up of 10 members, aged 24 to 35 years, and composed of seven women and three men. These panelists participated in weekly sensory training sessions for at least a year to be able to recognize and describe different aroma qualities. The sensory analyses were conducted in a sensory room according to international standards (ISO 8589, 2007) [33] with individual booths equipped with uniforms and glare-free white light (D65). Descriptors used were determined in preliminary sensory experiments as described by Steinhause et al. [34]. The reference compounds used as stimuli were: $10 \mu \mathrm{g} \mathrm{L}^{-1}$ of 2-acetyl-1-pyrroline (roasty); $100 \mu \mathrm{g} \mathrm{L}^{-1}$ of 3-methylbutanal (malty); $70 \mu \mathrm{g} \mathrm{L}{ }^{-1}$ of 2,3-butanedione (buttery); $50 \mu \mathrm{g} \mathrm{L}^{-1}$ of 4-vinyl-2-methoxyphenol (smoky); $100 \mu \mathrm{g} \mathrm{L}{ }^{-1}$ of methional (baked potato-like); and $50 \mu \mathrm{g} \mathrm{L}^{-1}$ of $\delta$-decalactone (oily/peach). During evaluation, the panelists had $5 \mathrm{~min}$ to rest after each set of samples was tested. All samples were repeated in triplicate. The intensities of the attributes were rated on a 7 point linear scale from 0 (not perceivable) to 3 (strongly perceivable) in steps of 0.5 by the panelists. The sensory data were analyzed in triplicate using the Student's $t$-test, and statistical analyses were performed using SPSS 20.0 (SPSS Inc., Chicago, IL, USA). In addition, all procedures performed in studies involving human participants were in accordance with the ethical standards of the institutional and/or national research committee and with the 1964 Helsinki Declaration and its later amendments or comparable ethical standards. The study protocol and consent procedure received ethical approval from the Institutional Review Board (IRB) of the University Putra Malaysia. Informed consent was obtained from all individual participants included in the study. 


\subsection{Aroma Model Recombinants and Omission Tests of the Fry Breads (UFBs and FBs)}

Reference standards of aroma constituents with OAVs above 1 (Table 2) were prepared in ethanolic solution [35]. The combined ethanolic stock solutions of the 11 aroma compounds $(500 \mu \mathrm{L})$ with OAVs $\geq 1$ was mixed with $30 \mathrm{~mL}$ of citrate buffer ( $\left.\mathrm{pH} 5.6 ; 0.1 \mathrm{~mol} \mathrm{~L}{ }^{-1}\right)$ and $30 \mathrm{~g}$ of free corn starch in a closed Teflon cup. The Teflon cup was stirred continuously for $15 \mathrm{~min}$ at room temperature (i.e., $29^{\circ} \mathrm{C}$ ). A triangle test was performed to determine the significance of one odorant on the aroma recombination models (UFBs and FBs) reported in (Table 4). For each of the models, a glass of the mixture $(20 \mathrm{~mL})$ was prepared by omitting one or a group of selected odorants from the complete recombination model (Table 5). This mixture and two other glasses containing the complete recombination models were presented to the sensory panel in a triangle test [36]. The results of the triangle tests were analyzed by comparing the total number of correct responses with the minimum number of responses required for statistical significance (ISO 4120, 2004) [37]. Panel performance was obtained by applying analysis of variance (ANOVA) to the sensory profile data. The data were analyzed using SAS statistical software (SAS Institute, Inc., Cary, NC, USA, 1996). The significance $\alpha$ was calculated according to the method of Callejo et al. [36]. In addition, each of the aroma models was evaluated orthonasally in comparison with the corresponding fry bread (i.e., UFB or FB) as described above (Section 2.6.).

Table 2. Aroma-active constituents in two differently produced fry breads.

\begin{tabular}{|c|c|c|c|c|c|c|}
\hline No & Compound $^{a}$ & Odor Note & $\begin{array}{l}\text { Retention Index } \\
\text { on DB-Wax }\end{array}$ & Fraction & $\begin{array}{l}\text { Flavor Dilution * } \\
\text { (UFB) }\end{array}$ & $\begin{array}{l}\text { Flavor } \\
\text { Dilution * (FB) }\end{array}$ \\
\hline 1 & 3-Methylbutanal & Malty & 900 & NB & 64 & 64 \\
\hline 2 & 2,3-Butanedione (diacetyl) & Buttery & 976 & NB & 32 & 32 \\
\hline 3 & 1-Octen-3-one & Mushroom & 1316 & NB & 4 & 4 \\
\hline 4 & 2-Acetyl-1-pyrroline & Roasty & 1325 & NB & 16 & 16 \\
\hline 5 & 2-Nonanone & Soapy/fruity & 1388 & NB & 8 & 8 \\
\hline 6 & Nonanal & Fatty & 1391 & NB & 8 & 8 \\
\hline 7 & Acetic acid & Vinegar & 1453 & A & 512 & 256 \\
\hline 8 & Methional & Baked potato & 1478 & NB & 64 & 64 \\
\hline 9 & (Z)-2-Nonenal & Fatty/green & 1511 & NB & 2 & 2 \\
\hline 10 & 2-Methypropanoic acid & Sweaty & 1514 & A & 8 & 8 \\
\hline 11 & (E)-2-Nonenal & Cucumber & 1542 & NB & 4 & 4 \\
\hline 12 & Butanoic acid & Sweaty & 1638 & A & 64 & 32 \\
\hline 13 & Phenyl acetaldehyde & Flowery & 1650 & NB & 16 & 16 \\
\hline 14 & 3-Methylbutanoic acid & Sweaty & 1674 & $\mathrm{~A}$ & 64 & 64 \\
\hline 15 & Pentanoic acid & Sweaty & 1698 & A & 8 & 8 \\
\hline 16 & $(E, E)$-2,4-Decadienal & Deep-fried & 1710 & NB & 32 & 32 \\
\hline 17 & Hexanoic acid & Sweaty & 1795 & A & 16 & 16 \\
\hline 18 & 4,5-Epoxy-(E)-2-decanal & Metallic & 2010 & NB & 4 & 4 \\
\hline 19 & 4-Hydroxy-2,5-dimethyl3(2H)-furanone & Caramel & 2030 & A & 32 & 32 \\
\hline 20 & Octanoic acid & Soapy/fatty & 2064 & A & 8 & 8 \\
\hline 21 & $\delta$-Decalactone & Oily/peach & 2112 & NB & 256 & 256 \\
\hline 22 & 2-Methoxy-4-vinylphenol & Smoky & 2203 & NB & 64 & 64 \\
\hline
\end{tabular}

a The compounds were identified by comparing the mass spectra through the mass spectra/electron ionization (MS/EI), the retention indices was detected on bonded low bleed wax capillary column (DB-Wax), and the odor note perceived at the sniffing port. * Flavor dilution (FD) determined by aroma extract dilution analysis (AEDA) for fry breads produced from unfrozen (UFB) and frozen (FB) doughs. NB: Neutral-basic fraction, A: acidic fraction.

\section{Results and Discussion}

\subsection{The Aroma-Active Constituents of Fry Breads}

A total of 22 aroma-active constituents were identified in the fry breads (i.e., fry breads produced from frozen dough, (FB) and those made from unfrozen dough (UFB)). Among these compounds, seven acids, eight aldehydes, four ketones, one heterocyclic compound, one furan, and a phenol were positively identified (Table 2). These aroma constituents exhibited an array of odor nuances such as malty, buttery, roast-like, baked potato-like, sweaty, deep-fried, caramel, smoky, and oily/peach-like. To establish differences among the flavors of the fry bread samples, the volatile fractions of the fry bread extracts were subjected to AEDA. The results of the AEDA and the identification experiments carried out are shown in Table 2. In the neutral-basic fraction (Table 2), the following aroma-active 
constituents, $\delta$-decalactone $(F D=256), 2$-methoxy-4-vinyl phenol $(F D=64)$, methional $(F D=64)$, 3-methylbutanal (FD = 64), 2,3-butanedione (FD = 32), and $(E, E)$-2,4-decadienal $(\mathrm{FD}=32)$, produced the highest FD factors in the UFB. This group was followed by 2-acetyl-1-pyrroline $(F D=16)$ and phenyl acetaldehyde $(\mathrm{FD}=16)$. For the acid fraction, acetic acid (FD = 512), butanoic acid $(\mathrm{FD}=64)$, 3-methylbutanoic acid (FD = 64), 4-hydroxy-2,5-dimethyl-3(2H)-furanone (FD = 32), and hexanoic acid $(F D=16)$ recorded the highest FD factors. In the case of the fry breads produced from the frozen dough (FB), the highest FD values were recorded for the following compounds detected in the neutral-basic fraction: $\delta$-decalactone (FD = 256), 2-methoxy-4-vinyl phenol (FD = 64), 3-methylbutanal $(\mathrm{FD}=64)$, methional $(\mathrm{FD}=64)$, 2,3-butanedione $(\mathrm{FD}=32)$, and $(E, E)-2,4$-decadienal $(\mathrm{FD}=32)$. On the other hand, acetic acid, butanoic acid, 3-methylbutanoic acid, and 4-hydroxy-2,5-dimethyl-3(2H) furanone recorded the highest FD values (32-256) in the acid fraction of the fry breads (FB).

\subsection{Aroma Quantitation in the Fry Breads}

To further evaluate the contribution of each aroma compound identified with high FD factors (i.e., FD factors $\geq 16$ ) to the overall aroma of the fry bread, the compounds were subjected to quantitation using SIDA. The quantitation results revealed that $\delta$-decalactone with the oily/peach note presented significantly $(p<0.05)$ high concentrations, with $1916 \mu \mathrm{g} \mathrm{kg}^{-1}$ and $1908 \mu \mathrm{g} \mathrm{kg} \mathrm{k}^{-1}$ in the UFB and FB, respectively (Table 3). It was followed by 2,3-butanedione $(924-925 \mu \mathrm{g} \mathrm{kg}-1)$, acetic acid $(668-716 \mu \mathrm{g} \mathrm{kg}-1)$, 3-methylbutanoic acid (618-621 $\left.\mu \mathrm{g} \mathrm{kg}^{-1}\right)$, and butanoic acid (348-350 $\mathrm{gg} \mathrm{kg}^{-1}$ ) in FB and UFB, respectively. Slightly lower concentrations were obtained for 4-hydroxy-2,5-dimethyl-3(2H)-furanone, 3-methylbutanal, (E,E)-2,4-decadienal, 2-methoxy-4-vinylphenol, phenyl acetaldehyde, and methional. 2-Acetyl-1-pyrroline recorded a value $<3.0 \mu \mathrm{g} \cdot \mathrm{kg}^{-1}$. It is worthy of note that $\delta$-decalactone, which had the highest concentration in both UFB and FB, had also been identified as a key aroma constituent in most fat-containing foods [38] such as butter oil [39] and puff pastries [40].

In addition, nearly all of the aroma-active constituents, disregarding their boiling point, polarity or functional group, decreased slightly (i.e., $<7 \%$ ) in the fry breads produced from the frozen doughs (FB) (Table 3). The only exception to this were 2,3-butanedione, 2-acetyl-1-pyrroline, and 2-methoxy-4-vinylphenol. The slight decreases (i.e., $<7 \%$ ) obtained between the FB and UFB were probably due to the frozen dough used in the production of FB. Studies have shown that freezing often results in the disruption of the gluten structure as a result of water migration brought about by crystal formation. This phenomenon results in the dissociation of starch granules from the gluten network [41]. The disruption of the starch granules is known to influence the interaction of starch with the volatile compounds as well as the retention of volatile compounds [42] Overall, the aldehydes and acids constituted the largest number of aroma constituents (FD $\geq 16$ ) (Table 3) in the fry breads. Aldehydes are typical lipid oxidation products that are associated with characteristic aroma of whole wheat bread [43]. In addition, aldehydes, such as 3-methylbutanal (malty) and phenyl acetaldehyde, identified in the fry breads can also be formed during the Maillard reaction [44]. Another route for the formation of the aldehydes could be through the amino acid biosynthetic pathway in which the aldehydes formed during the Ehrlich pathway is oxidized to their corresponding acids such as 3-methylbutanoic acid by aldehyde dehydrogenase [45]. It should be mentioned that acetic acid is also a well-known product of the Maillard reaction. 
Table 3. Concentration, odor thresholds, and odor activity values (OAVs) of aroma-active constituents $(\mathrm{FD} \geq 16)$ in fry breads.

\begin{tabular}{|c|c|c|c|c|c|c|}
\hline \multirow{2}{*}{ No } & \multirow{2}{*}{ Compound } & \multicolumn{2}{|c|}{ Concentration ( $\mu \mathrm{g} \mathrm{kg}^{-1}$ wet wt.) } & \multirow{2}{*}{$\begin{array}{l}\text { Threshold } \\
\text { in Starch * } \\
\left(\mu \mathrm{kg}^{-1}\right)\end{array}$} & \multicolumn{2}{|c|}{ (OAVs) } \\
\hline & & UFB & FB & & UFB & FB \\
\hline 1 & 3-Methylbutanal & $240 \pm 9.0^{\mathrm{a}}$ & $228 \pm 12.0^{\mathrm{b}}$ & 32 & 7.5 & 7.0 \\
\hline 2 & 2,3-Butanedione & $925 \pm 20.0^{\mathrm{a}}$ & $924 \pm 15.0^{\text {a }}$ & 6.5 & 142 & 142 \\
\hline 3 & 2-Acetyl-1-pyrroline & $2.5 \pm 0.1^{\mathrm{a}}$ & $2.4 \pm 0.1^{\mathrm{a}}$ & 0.0073 & 343 & 329 \\
\hline 4 & Acetic acid & $716 \pm 16.5^{\text {a }}$ & $668 \pm 12.0^{b}$ & 31,140 & $<1$ & $<1$ \\
\hline 5 & Methional & $75 \pm 9.2^{\mathrm{a}}$ & $72 \pm 11.5^{b}$ & 0.27 & 278 & 267 \\
\hline 6 & Butanoic acid & $350 \pm 8.8^{\mathrm{a}}$ & $348 \pm 5.5^{\mathrm{a}}$ & 100 & 3.5 & 3.5 \\
\hline 7 & Phenyl acetaldehyde & $107 \pm 5.0^{\mathrm{a}}$ & $102 \pm 7.1^{b}$ & ND & ND & ND \\
\hline 8 & 3-Methylbutanoic acid & $621 \pm 13.0^{\mathrm{a}}$ & $618 \pm 10.0^{b}$ & 6 & 104 & 103 \\
\hline 9 & $(E, E)-2,4$-Decadienal & $147 \pm 7.6^{\mathrm{a}}$ & $144 \pm 4.6^{\mathrm{b}}$ & 2.7 & 54 & 53 \\
\hline 10 & Hexanoic acid & $265 \pm 9.0^{\mathrm{a}}$ & $259 \pm 6.5^{b}$ & 11,000 & $<1$ & $<1$ \\
\hline 11 & 4-Hydroxy-2,5-dimethyl3(2H)-furanone & $265 \pm 8.0^{\mathrm{a}}$ & $263 \pm 7.1^{b}$ & 13 & 20 & 20 \\
\hline 12 & $\delta$-Decalactone & $1916 \pm 31.0^{\mathrm{a}}$ & $1908 \pm 23.0^{b}$ & ND & ND & ND \\
\hline 13 & 2-Methoxy-4-vinylphenol & $113 \pm 5.0^{\mathrm{a}}$ & $113 \pm 3.0^{\mathrm{a}}$ & 18.3 & 6 & 6 \\
\hline
\end{tabular}

* Thresholds in starch (Rychlik, Schieberle, and Grosch (1998) [46], OAV odor activity values on the basis of threshold in starch. UFB, fry breads produced from unfrozen doughs; FB, fry breads produced from frozen doughs; ND not detectable. Different letters within the same row represent significant differences.

\subsection{The Aroma-Active Constituents (FD $\geq 16$ ) and Their Potencies}

To elucidate the contribution and potency of each compound to the overall aroma of the fry breads, the OAVs of the aroma constituents with $\mathrm{FD} \geq 16$ were calculated on the basis of their odor thresholds in starch (Table 3). The fry breads exhibited more potencies for the following aroma notes: roasty/popcorn-like, baked-potato-like, buttery, and sweaty as revealed by the high values obtained for the OAVs of their corresponding compounds (e.g., 2-acetyl-1-pyrroline, (329-343); methional, (267-278); 2,3-butanedione, (142); and 3-methylbutanoic acid (103-104) for FB and UFB respectively) (Table 3). For instance, 2-acetyl-1-pyrroline exceeded its threshold by a factor of 343 in UFB and by 329 in FB (Table 3). Methional exceeded its threshold by a factor of 278 in UFB and by 267 in FB. A similar trend was obtained for 2,3-butanedione, 3-methylbutanoic acid, $(E, E)$-2,4-decadienal, and 4-hydroxy 2,5-dimethyl-3(2H)-furanone. Lower potencies were recorded for 3-methylbutanal (malty), 2-methoxy-4-vinylphenol (smoky), and butanoic acid. However, acetic acid and hexanoic acid had OAVs below 1, and it is assumed that these compounds did not contribute to the overall aroma of the fry breads.

\subsection{Aroma Profile Analysis and Aroma Simulation Models of the Fry Breads (UFBs and FBs)}

The results of the sensory evaluation of the different fry breads (UFBs and FBs) are shown in (Figure 1A, Table 4). The aroma profiles of the fry breads were characterized as roasty/popcorn-like, malty, buttery, baked potato-like, smoky, sweaty, deep-fried, and oily/peach-like. However, with the exception of the malty and buttery notes, the aroma profiles of the UFBs and FBs were quite similar. The malty and buttery nuances in the FB samples were less intense as compared to that of the UFB samples (Table 4). The Duncan's multiple comparison test results (Table 4) revealed that the eight attributes (roasty/popcorn-like, malty, buttery, baked potato-like, smoky, sweaty, deep-fried, and oily/peach-like) with different superscripts seemed to well explain their aroma characteristics. To validate this observation, recombination experiments were performed by mixing solutions of the pure reference compounds in the same amounts as obtained for both UFB and FB (Table 5). The recombination models were evaluated in parallel with the UFB and FB samples. Sensory results revealed that the recombinant models imitated well the flavor of the fry breads (Figure 1B,C). In addition, the roasty/popcorn aroma note was perceived as equally intense in the aroma models as well as in the fry breads. 


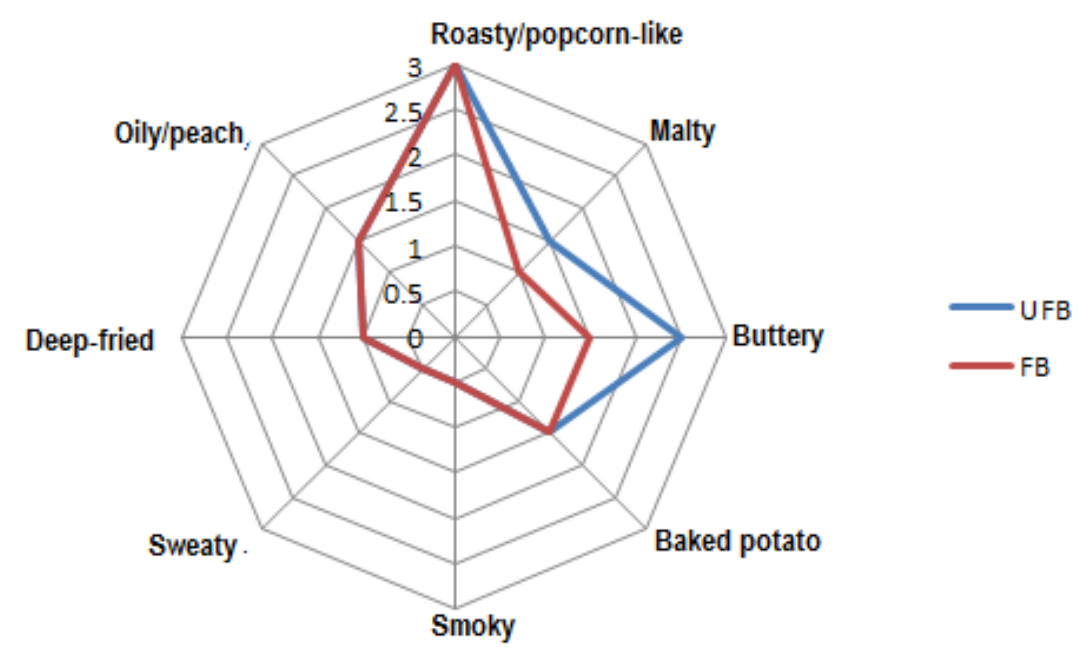

(A)

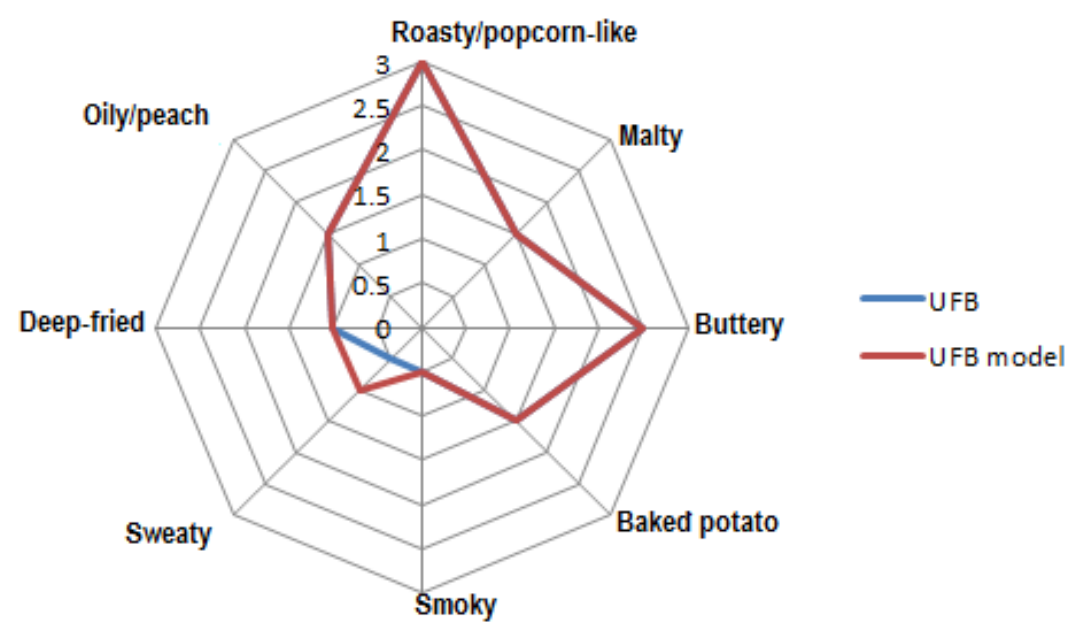

(B)

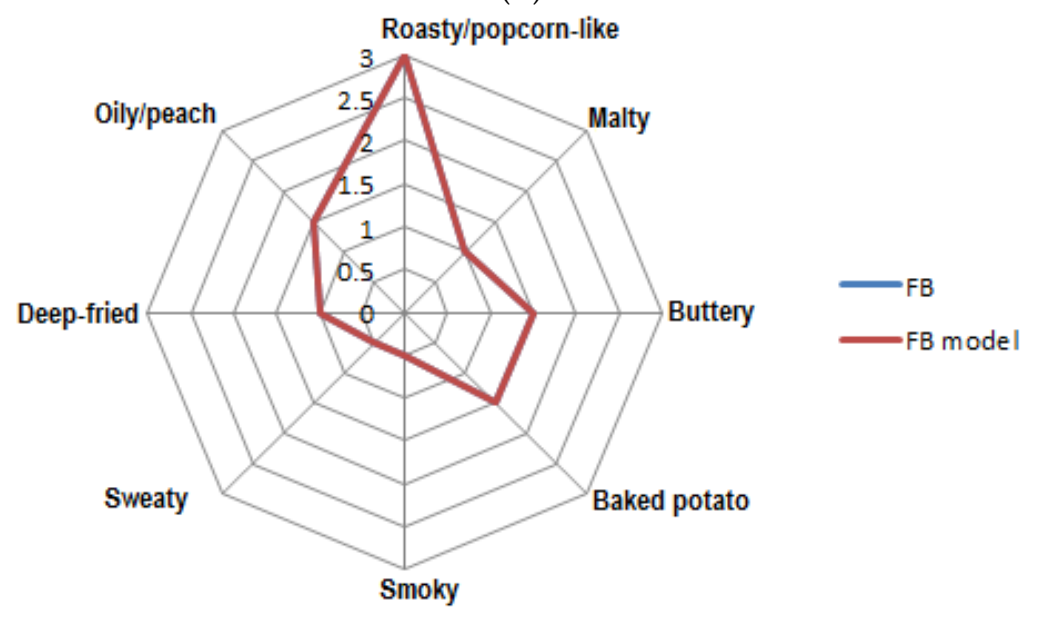

(C)

Figure 1. (A): Aroma profiles of fry breads produced from unfrozen dough (UFB) (blue line) and frozen dough (FB) (orange line). (B): A comparative aroma profile of FB (blue line) and its aroma model (FB-m) (orange line). (C): Aroma profile of UFB (blue line) and its aroma model (UFB-m) (orange line). 
Table 4. The mean scores of the eight attributes of the fry breads and the aroma models generated.

\begin{tabular}{cccccccc}
\hline \multirow{2}{*}{ Sensory Attributes } & \multicolumn{3}{c}{ Fry Breads } & \multicolumn{3}{c}{ Mean Scores of Fry Breads and Their Models } \\
\cline { 2 - 8 } & UFB & FB & $p$-Value & UFB & UFB Model & FB & FB Model \\
\hline Roasty/Popcorn & $3.0 \pm 0.32$ & $3.0 \pm 0.51$ & 0.01 & $3.0 \pm 0.4^{\mathrm{a}}$ & $3.0 \pm 0.3^{\mathrm{a}}$ & $3.0 \pm 0.2^{\mathrm{A}}$ & $3.0 \pm 0.4^{\mathrm{A}}$ \\
Malty & $1.5 \pm 0.06$ & $1.0 \pm 0.10$ & 0.00 & $1.5 \pm 0.1^{\mathrm{a}}$ & $1.5 \pm 0.4^{\mathrm{a}}$ & $1.0 \pm 0.0^{\mathrm{A}}$ & $1.0 \pm 0.1^{\mathrm{A}}$ \\
Buttery & $2.5 \pm 0.40$ & $1.5 \pm 0.03$ & 0.07 & $2.5 \pm 0.4^{\mathrm{a}}$ & $2.5 \pm 0.8^{\mathrm{a}}$ & $1.5 \pm 0.1^{\mathrm{A}}$ & $1.5^{\mathrm{a}} \pm 0.3^{\mathrm{A}}$ \\
Baked potato & $1.5 \pm 0.17$ & $1.5 \pm 0.10$ & 0.00 & $1.5 \pm 0.2^{\mathrm{a}}$ & $1.5 \pm 0.1^{\mathrm{a}}$ & $1.5^{\mathrm{a}} \pm .1^{\mathrm{A}}$ & $1.5^{\mathrm{a}} \pm 0.3^{\mathrm{A}}$ \\
Smoky & $0.5 \pm 0.00$ & $0.5 \pm 0.00$ & 0.00 & $0.5 \pm 0.0^{\mathrm{a}}$ & $0.5 \pm 0.1^{\mathrm{a}}$ & $0.5 \pm 0.0^{\mathrm{A}}$ & $0.5 \pm 0.1^{\mathrm{A}}$ \\
Sweaty & $0.5 \pm 0.01$ & $0.5 \pm 0.00$ & 0.00 & $0.5 \pm 0.0^{\mathrm{b}}$ & $1.0 \pm 0.3^{\mathrm{a}}$ & $0.5 \pm 0.1^{\mathrm{A}}$ & $0.5 \pm 0.0^{\mathrm{A}}$ \\
Deep-fried & $1.0 \pm 0.02$ & $1.0 \pm 0.00$ & 0.00 & $1.0 \pm 0.1^{\mathrm{a}}$ & $1.0 \pm 0.1^{\mathrm{a}}$ & $1.0 \pm 0.1^{\mathrm{A}}$ & $1.0^{\mathrm{a}} \pm 0.0^{\mathrm{A}}$ \\
Oily/peach & $1.5 \pm 0.12$ & $1.5 \pm 0.04$ & 0.00 & $1.5 \pm 0.2^{\mathrm{a}}$ & $1.5 \pm 0.3^{\mathrm{a}}$ & $1.5 \pm 0.1^{\mathrm{A}}$ & $1.5 \pm 0.4^{\mathrm{A}}$ \\
\hline A, B, C: a, b, c, Different letters within the same row represent significant differences $(p<0.05)(\mathrm{n}=30,10$ panelists with \\
three replications), $p$-values among fry bread samples obtained by Student's $t$-test. UFB, fry bread produced from \\
unfrozen dough; FB, fry bread from frozen dough.
\end{tabular}

Table 5. Aroma model compositions for fry breads (UFB and FB).

\begin{tabular}{|c|c|c|c|c|}
\hline \multirow{2}{*}{ No } & \multirow{2}{*}{ Compounds } & \multirow{2}{*}{ Odor Notes } & \multicolumn{2}{|c|}{ Concentration $\left(\mu \mathrm{g} \mathrm{L}^{-1}\right)$ * } \\
\hline & & & UFB & FB \\
\hline 1 & 3-Methylbutanal & Malty & 240 & 228 \\
\hline 2 & 2,3-Butanedione & Buttery & 925 & 924 \\
\hline 3 & 2-Acetyl-1-pyrroline & Popcorn/roast & 2.5 & 2.4 \\
\hline 4 & Methional & Baked potato & 75 & 72 \\
\hline 5 & Butanoic acid & Sweaty & 350 & 348 \\
\hline 6 & Phenyl acetaldehyde & Flowery/honey & 107 & 102 \\
\hline 7 & 3-Methylbutanoic acid & Sweaty & 621 & 618 \\
\hline 8 & $(E, E)$-2,4-Decadienal & Deep-fried & 147 & 144 \\
\hline 9 & 4-Hydroxy-2,5-dimethyl-3(2H)- furanone & Caramel-like & 265 & 263 \\
\hline 10 & 2-Methoxy-4-vinylphenol & Smoky & 113 & 113 \\
\hline 11 & $\delta$-Decalactone ${ }^{a}$ & Oily/peach & 1916 & 1908 \\
\hline
\end{tabular}

* Ethanolic solutions of aroma compounds dissolved in free corn starch. ${ }^{\text {a }} \delta$-Decalactone was added because of its high concentrations.

\subsection{Omission Tests}

To assess the contribution of individual compound to the overall aroma of the fry bread (UFB and FB), omission tests were conducted on the fry bread aroma models (Table 6) [47]. In this study, 7 aroma omission models (M1-M7) comprised of either a single or group of compounds were prepared. Each of the omission models was evaluated in triangular experiments with two complete recombination models (Table 6). The results revealed that, when the entire group of aldehydes (M1) was omitted, their omission from the complete recombination model could be detected by 9 out of the 10 assessors. This is an indication of the importance of these aldehydes (i.e., 3-methylbutanal, methional, phenyl acetaldehyde and $(E, E)$-2,4-decadienal) in the overall aroma of the fry breads.

In the second group, the acids (butanoic acid and 3-methylbutanoic acid) were omitted. The result of the omission of all the acids from the complete recombination models showed that 8 out of the 10 assessors were able to detect between the omission model and the complete recombination models. This shows that the acids also influence the overall aroma of the fry breads. Similar results were obtained when all ketones (M3) were omitted. Omission of single compounds, such as 2-methoxy-4-vinylphenol (smoky) (M4) or 4-hydroxy-2,5-dimethyl-3(2H)-furanone (caramel-like) (M6), resulted in less significant $(p \leq 0.05)$ reductions in the characteristics aroma of the fry breads. Only 7 out of the 10 assessors could detect the omission of either compound. However, the omission of 2-acetyl-1-pyrroline (popcorn-like) (M5) or $\delta$-decalactone (oily/peach) (M7) resulted in a highly significant $(p \leq 0.001)$ reduction in the characteristic aroma of the fry breads. In the case of 2-acetyl-1-pyrroline, all 10 assessors were able to detect its omission from the complete recombination models. 
Table 6. Omission analysis on the fry bread aroma models (UFB and FB).

\begin{tabular}{|c|c|c|c|c|c|}
\hline \multirow{2}{*}{$\begin{array}{l}\text { Odorant Groups } \\
\text { Aldehydes (M1) }\end{array}$} & \multirow{2}{*}{$\begin{array}{c}\text { Aroma Notes } \\
\begin{array}{c}\text { Malty, baked potato-like, } \\
\text { flowery, deep-fried }\end{array}\end{array}$} & \multirow{2}{*}{$\begin{array}{c}\text { Compounds Omitted } \\
\text { 3-Methylbutanal, Methional, Phenyl } \\
\text { acetaldehyde, }(E, E) \text {-2,4-Decadienal, }\end{array}$} & \multicolumn{2}{|c|}{$\begin{array}{l}\text { No of Correct Judgments a } \\
\text { UFB FB }\end{array}$} & \multirow{2}{*}{ Significance $^{\mathrm{b}}$} \\
\hline & & & $9 / 10$ & $9 / 10$ & \\
\hline Ketones (M3) & Buttery, Caramel-like & $\begin{array}{l}\text { 2,3-Butanedione, } \\
\text { 4-Hydroxy-2,5-dimethyl-3(2H)-furanone }\end{array}$ & $8 / 10$ & $8 / 10$ & ** \\
\hline Phenols (M4) & Smoky & 2-Methoxy-4-vinylphenol & $7 / 10$ & $7 / 10$ & $*$ \\
\hline M7 & Oily/peach & $\delta$-Decalactone & $8 / 10$ & $8 / 10$ & ** \\
\hline
\end{tabular}

${ }^{a}$ Number of correct judgments from 10 assessors; ${ }^{b}$ Significance: ${ }^{*}$ significant $(\alpha \leq 0.05) ;{ }^{* *}$ highly significant $(\alpha \leq 0.01)$; ${ }^{* * *}$ very highly significant $(\alpha \leq 0.001)$; M1-M7 Models. UFB, fry bread from unfrozen dough; FB, fry bread from frozen dough.

\section{Conclusions}

In conclusion, differences in the aroma-active constituents of fry breads produced from frozen doughs (FBs) and freshly made doughs (UFBs) were characterized for the first time. A total of twenty-two aroma constituents were identified in the fry breads. The results of the OAVs and sensory studies showed that the aroma profiles of the fry breads were characterized as roasty/popcorn-like, malty, buttery, baked potato-like, smoky, sweaty, deep-fried, and oily/peach-like. However, with the exception of the malty and buttery notes, the aroma profiles of UFBs and FBs were quite similar, and the malty and buttery nuances in the FB samples were less intense as compared to that of the UFB samples. Aroma-active constituents, such as $\delta$-decalactone (oily/peach), 2-acetyl-1-pyrroline (roasty/popcorn-like), 3-methylbutanal (malty), methional (baked potato-like), 2,3-butanedione (buttery), phenyl acetaldehyde (flowery), (E,E)-2,4-decadienal (deep-fried), butanoic acid, and 3-methylbutanoic acid, were identified as the key aroma constituents of fry bread. In addition, 3-methoxy-4-vinylphenol (smoky) and 4-hydroxy-2,5-dimethyl-3(2H)-furanone (caramel-like) were identified as important aroma constituents of fry bread. Finally, these findings establish a basis for further work on the identification of the taste-active food components in fry breads as well as consumers' preferences for the differently produced fry breads.

Author Contributions: O.L. supervision and funding acquisition and writing, review, and editing of final paper; F.D. formal analysis, data collection, writing of draft. All authors have read and agreed to the published version of the manuscript.

Funding: Financial support for this research was provided by the University Putra Malaysia research scheme (Grant No. 9478500).

Conflicts of Interest: The authors declare they do not have any conflict of interest.

\section{References}

1. Pico, J.; Bernal, M.; Gomez, M. Wheat bread aroma compounds in crumb and crust a review. Food Res. Int. 2015, 75, 200-215. [CrossRef]

2. Ying, S.; Lasekan, O.; Naidu, K.; Lasekan, A. Headspace solid-phase micro extraction gas chromatography-mass spectrometry and gas chromatography-olfactometry analysis of volatile compounds in pineapple breads. Molecules 2012, 17, 13795-13812. [CrossRef] [PubMed]

3. Paraskevopoulos, A.; Chrysanthou, A.; Koutidou, M. Characterization of volatile compounds of lupin protein isolate-enriched wheat flour bread. Food Res. Int. 2012, 48, 568-577. [CrossRef]

4. Birch, A.N.; Petersen, M.A.; Arnsberg, N.; Hansen, A.S. Influence of commercial Baker's yeasts on bread aroma profiles. Food Res. Int. 2013, 52, 160-166. [CrossRef]

5. Quilez, J.; Ruiz, J.A.; Romero, M.P. Relationships between sensory flavor Evaluatio and volatile and non-volatile compounds in commercial wheat bread type Baguette. J. Food Sci. 2006, 71, S423-S427. [CrossRef]

6. Rohleder, A.R.; Scherf, K.A.; Schieberle, P.; Koehler, P. Quantitative analyses of key odorants and their precursors reveal differences in the aroma of gluten-free rice bread and wheat bread. J. Agric. Food Chem. 2019, 67, 11179-11188. [CrossRef] 
7. Hansen, A.; Schieberle, P. Generation of aroma compounds during sourdough fermentation: Applied and fundamental aspects. Trends Food Sci. Technol. 2005, 16, 85-94. [CrossRef]

8. Moris, C.; Moris, G.A. The effect of insulin and fructo-oligosaccharide supplementation on the texture rheological and sensory properties of bread and their role in weight management: A review. Food Chem. 2012, 133, 237-248. [CrossRef]

9. Jiang, J.; Coffey, P.; Toohey, B. Improvement of odor intensity measurement using dynamic olfactrometry. J. Air Waste Manag. Assoc. 1995, 56, 675-683. [CrossRef]

10. Poinot, P.; Grua-Priol, J.; Arvisenet, G.; Rannou, C.; Semenou, M.; Le Bail, A.; Prost, C. Optimization of HS-SPME to study representativeness of partially baked bread odorant extracts. Food Res. Int. 2007, 40, 1170-1184. [CrossRef]

11. Schieberle, P.; Grosch, W. Changes in the concentration of potent crust odorants during storage of white bread. Flavor Fragr. J. 1992, 7, 213-218. [CrossRef]

12. Czerny, M.; Schieberle, P. Important aroma compounds in freshly ground whole meal and white wheat flour-identification and quantitative changes during sourdough fermentation. J. Agric. Food Chem. 2002, 50, 6835-6840. [CrossRef]

13. Schoenauer, S.; Schieberle, P. Characterization of the key aroma compounds in the crust of soft pretzels by application of the sensomics concept. J. Agric. Food Chem. 2019, 67, 7110-7119. [CrossRef] [PubMed]

14. Sahin, B.; Schieberle, P. Characterization of the key aroma compounds in yeast dumplings by means of the sensomics concept. J. Agric. Food Chem. 2019, 67, 2973-2979. [CrossRef] [PubMed]

15. Census Bureau of Population. Population of American Indians. Available online: https://www.census.gov/ topics/population (accessed on 17 July 2020).

16. Lewis, C. Fry bread wars: Bio politics and the consequences of selective United States healthcare practices for American Indians. Food Cult. Soc. 2018, 21, 427-448. [CrossRef]

17. Parker, J.K. Introduction to Aroma Compounds in Foods. In Flavor Development, Analysis and Perception in Food and Beverages-A Volume in Woodland Publishing Series in Food Science; Technology \& Nutrition: Cambridge, UK, 2015; pp. 4-30. [CrossRef]

18. Schieberle, H.T.; Schieberle, P.; Hofmann, T. Food Flavor; Henryk, J., Ed.; CRC Press: Boca Raton, FL, USA, 2011; pp. 413-438.

19. Schieberle, P.; Grosch, W. Identification of flavor compounds from the crust of rye Bread. Z. Lebensm.-Unters. Forsch. 1983, 177, 173-180. [CrossRef]

20. Schieberle, P.; Grosch, W. Evaluation of the flavor of wheat and rye bread crusts by aroma extracts dilution analysis. Z. Lebensm.-Unters. Forsch. 1987, 185, 111-113. [CrossRef]

21. Schieberle, P.; Hofmann, T. Evaluation of the character impact odorants in fresh strawberry juice by quantitative measurements and sensory studies on model mixtures. J. Agric. Food Chem. 1997, 45, 227-232. [CrossRef]

22. Guth, H.; Grosch, W. Deterioration of soybean oil: Quantitation of primary flavor compounds using s stable isotope dilution assay. LWT-Food Sci. Technol. 1990, 23, 513-522.

23. Guth, H.; Grosch, W. Identification of the character impact odorants of stewed beef juice by instrumental and sensory studies. J. Agric. Food Chem. 1994, 42, 2862-2866. [CrossRef]

24. Czerny, M.; Grosch, W. Quantitation of character-impact odor compounds of roasted beef. Z. Lebensm.-Unters. Forsch. 1993, 196, 417-422. [CrossRef]

25. Poisson, L.; Schieberle, P. Characterization of the key aroma compounds in an American bourbon whisky by quantitative measurements, aroma recombination, and omission studies. J. Agric. Food Chem. 2008, 56, 5820-5826. [CrossRef] [PubMed]

26. Blank, I.; Sen, A.; Grosch, W. Potent odorants of the roasted powder and brew of Arabica coffee. Z. Lebensm.-Unters. Forsch. 1992, 195, 239-245. [CrossRef]

27. Schieberle, P.; Gassenmeir, K.; Guth, H.; Sen, A.; Grosch, W. Character impact odor compounds of different kinds of butter. LWT-Food Sci. Technol. 1993, 26, 347-356. [CrossRef]

28. Engel, W.; Bahr, W.; Schieberle, P. Solvent assisted flavor evaporation (SAFE) a new and versatile technique for the careful and direct isolation of aroma compounds from complex matrices. Eur. Food Res. Technol. 1999, 209, 237-241. [CrossRef]

29. Lasekan, O.; $\mathrm{Ng}$, S.S. Key volatile aroma compounds of three black velvet tamarinds (Dialium) fruit species. Food Chem. 2015, 168, 561-565. [CrossRef] 
30. Lasekan, O.; Yap, S.P. Characterization of the aroma compounds in fresh and dried sapodilla (Manikara zapota, L.) by the application of aroma extracts dilution analysis. CyTA-J. Food 2018, 16, 801-806. [CrossRef]

31. Lasekan, O.; Buettner, A.; Christlbauer, M. Investigation of important odorants of Palm wine (Elaeis guineensis). Food Chem. 2007, 105, 15-23. [CrossRef]

32. Guth, H.; Grosch, W. Aroma compounds in extruded oat flour. Changes during processing. Z. Lebensm.-Unters. Forsch. 1993, 196, 22-28. [CrossRef]

33. ISO 8589: 2007. Sensory Analysis, General Guidance for the Design of Test Rooms; International Organization for Standardization: Geneva, Switzerland, 2007.

34. Steinhaus, M.; Sinuco, D.; Polster, J.; Osorio, C.; Schieberle, P. Characterization of the key aroma compounds in pink guava (Psidium guajava, L.) by means of aroma re-engineering experiments and omission tests. J. Agric. Food Chem. 2009, 57, 2882-2888. [CrossRef]

35. Lasekan, O.; Khatib, A.; Juhari, H.; Patiram, P.; Lasekan, A. Headspace solid phase micro-extraction gas chromatography-mass spectrometry determination of volatile compounds in different varieties of African star apple fruit (Chrysophillum albidum). Food Chem. 2013, 141, 2089-2097. [CrossRef] [PubMed]

36. Callejo, M.N.; Vargas-Kostiuk, M.E.; Rodriguez-Quijand, M. Selection, training and validation process of a sensory panel for bread analysis: Influence of cultivar on quality of breads made from common wheat and spelt wheat. J. Cereal Sci. 2015, 61, 55-62. [CrossRef]

37. ISO 4120: 2004. Sensory Analysis, Triangular Test; International Organization for Standardization: Geneva, Switzerland, 2004.

38. Boratyriski, F.; Dancewicz, K.; Paprocka, M.; Gabrys, B.; Wawrzericzyk, C. Chemo-enzymatic synthesis of optically active $\gamma$ - and $\delta$-decalactones and their effect on aphid probing, feeding and setting behavior. PLOS ONE 2016, 11, e0146160.

39. Widder, S.; Sen, A.; Grosch, W. Changes in the flavor of butter oil during storage Identification of potent odorants. Z. Lebensm.-Unters. Forsch. 1991, 193, 32-35. [CrossRef]

40. Gassenmeir, K.; Schieberle, P. Comparison of important odorants in puff-pastries prepared with butter or margarine. LWT-Food Sci. Technol. 1994, 27, 282-288. [CrossRef]

41. Zounis, S.; Quail, K.J.; Wootton, M.; Dickson, M.R. Studying frozen dough structure using low-temperature scanning electron microscopy. J. Cereal Sci. 2002, 35, 135-147. [CrossRef]

42. Arvisenet, G.; Le Bail, P.; Voilley, A.; Cayot, N. Influence of physicochemical interactions between amylose and aroma compounds on the reaction of aroma in food-like matrices. J. Agric. Food Chem. 2002, 50, 7088-7093. [CrossRef]

43. Moskowitz, M.R.; Bin, Q.; Peterson, D.G.; Elias, R.J. Influence of endogenous ferulic acid in whole wheat flour on bread crust aroma. J. Agric. Food Chem. 2012, 60, 11245-11252. [CrossRef]

44. Prost, C.; Poinot, P.; Rannou, C.; Arvisenet, G. Bread aroma. In Bread Making, Improving Quality; Cauvain, S.P., Ed.; Woodhead: Cambridge, UK, 2012; pp. 523-561.

45. Birch, A.N.; Petersen, M.A.; Hansen, A.S. Aroma of wheat bread crumb. Cereal Chem. 2014, 91, 105-114. [CrossRef]

46. Rychlik, M.; Schieberle, P.; Grosch, W. Compilation of Odor Thresholds, Odor Qualities and Retention Indices of Key Food Odorants; Deutsche Forschungsanstalt fur Lebensmittelchemie: Garching, Germany, 1998; ISBN 3-9803426-5-4.

47. Grosch, W. Evaluation of key odorants of foods by dilution experiments, aroma models and omission. Chem. Senses 2001, 26, 533-545. [CrossRef]

(C) 2020 by the authors. Licensee MDPI, Basel, Switzerland. This article is an open access article distributed under the terms and conditions of the Creative Commons Attribution (CC BY) license (http://creativecommons.org/licenses/by/4.0/). 